\title{
Malignancies in UK children with HIV infection acquired from mother to child transmission
}

\author{
J A Evans, D M Gibb, F J Holland, P A Tookey, J Pritchard, A E Ades
}

Department of Paediatrics, Imperial College School of Medicine at St Mary's, London

J A Evans

Department of Epidemiology and Biostatistics, Institute of Child Health, London

D M Gibb

F J Holland

P A Tookey

A E Ades

Department of Haematology and Oncology, Great Ormond Street Hospitals for Children NHS Trust, London

J Pritchard

Correspondence to: Dr D M Gibb, Department of Epidemiology and Biostatistics, Institute of Child Health, 30 Guilford Street, London WC1N 1EH.

Accepted 19 November 1996

\begin{abstract}
By April 1995, 302 cases of vertically acquired HIV infection had been reported through the British Paediatric Association Surveillance Unit. Over $50 \%$ of these children had developed an AIDS indicator disease, including nine malignancies (seven cases of non-Hodgkin's lymphoma (NHL) and two of Kaposi's sarcoma). There were two other malignancies that were not AIDS indicator diseases. In children less than 5 years of age the incidence of NHL was approximately 2500 times greater than expected in the UK child population. Three children presented with NHL as their AIDS indicator disease and four developed NHL at a median of 14 (range 10-19) months after the initial diagnosis of AIDS. Six of the seven children died at a median of 6.5 (range 2-14) months after the diagnosis of NHL. The seventh child responded to treatment and is alive nearly four years later. Histology was available in five cases, of which four were of $B$ cell and one of $T$ cell origin. Epstein-Barr virus was detected in all three patients with NHL where it was sought; all had B cell lymphomas. Although comparatively rare, malignancies occur in children infected with HIV and may be the presenting illness. Paediatricians now need to consider HIV infection as a predisposing cause of childhood cancer, especially NHL.

(Arch Dis Child 1997;76:330-333)
\end{abstract}

Keywords: HIV infection; malignancy; non-Hodgkin's lymphoma

The risk of developing a malignancy, particularly a lymphoma, is higher in subjects with primary and secondary immunodeficiencies. ${ }^{1-3}$ Kaposi's sarcoma and lymphoma are the most common malignancies associated with HIV infection and are classified as 'AIDS indicator diseases'. ${ }^{45}$ Other cancers such as cervical carcinoma and soft tissue sarcomas are also associated with HIV. ${ }^{6}$ In children with HIV infection acquired from mother to child (vertical) transmission, the incidence of neoplastic disease is also increased, with the major malignancy being non-Hodgkin's lymphoma (NHL). In Europe and the USA, NHL accounts for $0.9-1.4 \%$ of first AIDS indicator diseases in children vertically infected with HIV. ${ }^{8}$ This is an underestimate of the overall incidence, however, as children who develop NHL after their first diagnosis of AIDS are, by definition, excluded. In contrast, Kaposi's sarcoma is rare in vertically acquired HIV infection outside areas of endemic Kaposi's sarcoma in Africa. Other cancers have been sporadically reported in children infected with HIV, but these may be coincidental rather than a direct or indirect consequence of HIV disease.

The purpose of this paper is to describe the malignancies occurring in UK children vertically infected with HIV, with particular emphasis on NHL, and to estimate the risk of NHL in this group of children.

\section{Patients and methods}

In the British Isles, the surveillance of children with HIV infection is carried out through an active confidential reporting scheme. Paediatricians report cases of children seropositive for HIV through the monthly reporting scheme of the British Paediatric Association Surveillance Unit (BPASU), which has a response rate of over $90 \%$. Details of the surveillance scheme, which has been operating since 1989, have been reported previously. ${ }^{9}$ Each report is followed up using a standard questionnaire.

The clinical data collected about infected children include the details and dates of AIDS indicator diseases, other HIV related symptoms and signs, prophylactic and antiretroviral treatment, and $\mathrm{T}$ cell subset results. The infected children are followed up annually to monitor their clinical progression, the age at onset of AIDS, and the age at death. Children reported to have a malignancy were identified through this source and further clinical and pathological data obtained from the reporting paediatricians.

The increased risk of NHL in children with vertically acquired HIV infection was estimated by calculating the ratio of observed cases of NHL in HIV infected children born in England, Wales, and Scotland with the expected number derived from age specific childhood NHL cancer rates for the same geographical area between 1978 and $1987 .{ }^{10}$ The annual number of births where the child was vertically infected with HIV can be estimated from reports of AIDS in vertically infected children born in the UK and from estimates of vertical transmission rates and AIDS incubation periods derived from prospective studies. ${ }^{11}$ The number of years at risk of NHL in HIV infected children were then derived using data on mortality from the European Collaborative Study of children born to HIV infected women. ${ }^{12}$ Analyses were confined to children 
Table 1 Details of children with NHL and HIV infection acquired through mother to child transmission

\begin{tabular}{|c|c|c|c|c|c|c|c|c|c|c|c|}
\hline $\begin{array}{l}\text { Patient } \\
\text { No }\end{array}$ & Sex & $\begin{array}{l}\text { Ethnic } \\
\text { origin }\end{array}$ & $\begin{array}{l}\text { Age at } \\
\text { HIV } \\
\text { diagnosis } \\
\text { (years) }\end{array}$ & $\begin{array}{l}\text { Age at } \\
\text { AIDS } \\
\text { diagnosis } \\
\text { (years) }\end{array}$ & $\begin{array}{l}\text { Age at } \\
\text { NHL } \\
\text { diagnosis } \\
\text { (years) }\end{array}$ & $\begin{array}{l}\text { Age at } \\
\text { death } \\
\text { (years) }\end{array}$ & $\begin{array}{l}\text { AIDS } \\
\text { defining } \\
\text { illness }\end{array}$ & $\begin{array}{l}\text { CD4 } \\
\text { count } \\
\text { per } \\
\text { mm }^{3 \star}\end{array}$ & $\begin{array}{l}\text { Site and histology } \\
\text { of lymphoma }\end{array}$ & Treatment & Cause of death \\
\hline 1 & M & White & $\dagger$ & 0.7 & 2.1 & 3.4 & FTT & $\begin{array}{l}40 \\
(-1)\end{array}$ & $\begin{array}{l}\text { Left ear and } \\
\text { cerebral }\end{array}$ & $\begin{array}{l}\text { Surgery/radiotherapy/COMP } \times 1, \\
\text { vincristine }+ \text { prednisolone } \times 2\end{array}$ & NHL \\
\hline 2 & $\mathrm{~F}$ & Mixed & $\dagger$ & 2.8 & 2.8 & 3.3 & NHL & $\begin{array}{l}190 \\
(0)\end{array}$ & Abdominal & Unknown & NHL \\
\hline 3 & $\mathrm{~F}$ & African & $\dagger$ & 1.3 & 2.4 & 2.7 & Enc & $\begin{array}{l}16 \\
(-2)\end{array}$ & $\begin{array}{l}\text { Cerebral } \\
\quad \text { (presumptive) }\end{array}$ & Palliation & NHL \\
\hline 4 & M & African & 0.15 & 0.15 & 1.0 & 1.2 & PCP & $\begin{array}{l}410 \\
(-4)\end{array}$ & Disseminated & Palliation & $\begin{array}{l}\text { Haemorrhage from } \\
\text { NHL }\end{array}$ \\
\hline 5 & $\mathrm{~F}$ & White & 1.0 & 1.0 & 2.2 & 3.3 & $\begin{array}{l}\text { FTT/ } \\
\text { Enc }\end{array}$ & $\begin{array}{l}5 \\
(+2)\end{array}$ & Tonsil & Vincristine + prednisolone & $\begin{array}{l}\text { Septicaemia; no } \\
\text { recurrence of } \\
\text { NHL }\end{array}$ \\
\hline 6 & M & Hispanic & 5.8 & 4.9 & 4.9 & $\ddagger$ & NHL & $\begin{array}{l}390 \\
(+13)\end{array}$ & Nasopharyngeal & NHL protocol 903 & Alive, age 8.5 years \\
\hline 7 & M & African & $\dagger$ & 2.4 & 2.4 & 3.0 & NHL & $\begin{array}{l}40 \\
(0)\end{array}$ & Soft palate & VP16 + prednisolone & NHL \\
\hline
\end{tabular}

* Figures in parentheses indicate timing of CD4 count measurements (in months) relative to NHL diagnosis.

$\dagger$ Mother known to have HIV infection during pregnancy.

$\mp$ This is the only child still alive.

FTT $=$ failure to thrive; Enc $=$ HIV encephalopathy; PCP = Pneumocystis carinii pneumonia; COMP $=$ cyclophosphamide, vincristine, methotrexate, prednisolone .

less than 5 years of age as follow up data on older children infected with HIV were limited.

\section{Results}

By June 1995, 302 children with confirmed HIV infection as a result of vertical transmission had been reported from centres in England, Wales, and Scotland. ${ }^{13}$ Of these, 164 had AIDS and 95 had died. Eleven children had developed a malignancy. Two children, one of Ugandan and one of Zambian origin, had Kaposi's sarcoma and have been reported elsewhere. ${ }^{14} 15$

Two children had developed malignancies which were not defining of AIDS. One boy developed a Ewing's sarcoma of a fibula at 6 years of age and died six months later of HIV encephalopathy. ${ }^{16}$ The second child was a girl who developed a cerebral rhabdoid tumour at the age of 5.5 years, which was successfully treated with surgery and radiotherapy. She remains well at 11 years of age.

\section{NON-HODGKIN'S LYMPHOMA}

Seven children were reported to have NHL and their details are shown in table 1 . There was no significant association of NHL with ethnic group or maternal risk factors for acquiring HIV, such as intravenous drug use. Four mothers knew their HIV diagnosis before their child was born, but in three cases HIV was diagnosed only after the child presented with an AIDS indicator disease. The median age of the children at the diagnosis of AIDS was 14 months (range 3-33 months).

NHL was the initial AIDS indicator disease in three children, and in the remaining four it was diagnosed between 10 and 19 months (median 14 months) after the initial diagnosis of AIDS. All children had low CD4 counts for their age ${ }^{17}$ around the time of diagnosis of NHL, with the exception of one child whose HIV status was ascertained retrospectively after treatment for B cell lymphoma had been completed. This child is still alive nearly four years later, whereas the remaining children had all died at a mean of six (range 2-14) months after the diagnosis of NHL. Five of the six deaths were related to NHL. The two children with cerebral lymphoma were diagnosed on clinical and radiological grounds without histological confirmation, although one appeared to be a recurrence of a definitively diagnosed lymphoma (patient 1); the abnormalities seen with computed tomography were compatible with either lymphoma or toxoplasmosis, but both patients were unresponsive to treatment for toxoplasmosis.

\section{TREATMENT}

In two patients (patients 3 and 4), both of whom already had AIDS, no specific treatment was given for the lymphoma. The tonsillar lymphoma of patient 5 responded to a 'palliative' five week course of vincristine and high dose steroids; this patient continued to receive a small dose of steroids until her death 14 months later. Although no necropsy was performed there was no clinical evidence of a recurrence of the lymphoma. Patient 1 initially presented with a lymphoma affecting his left ear which responded to local radiotherapy; the recurrent presumed cerebral lymphoma was treated with one course of a modified COMP protocol (cyclophosphamide, vincristine, methotrexate, prednisolone), but had a limited response and major toxicity. Patients 6 and 7 also received specific chemotherapy; the treatment received by patient 2 is unknown (table 1). In patients 2 and 7 the lymphoma progressed rapidly and both children died within six months of presentation. Only the older boy with B cell NHL (patient 6) completed a nine month standard intensive chemotherapy regimen (NHL protocol 903); he remains free of lymphoma nearly four years later.

In the five patients where histology was available, four were of B cell origin and one was a $\mathrm{T}$ cell lymphoma. Three of the $\mathrm{B}$ cell lymphomas were high grade diffuse large cell malignancies, as shown in fig $1 \mathrm{~A}$ (patient 5). The fourth (patient 6) is a classic 'Burkitt's lymphoma' (fig 1B). Viral studies were undertaken in three children (patients 4,5, and 6), all with B cell NHL; all three were positive for the Epstein-Barr virus latent membrane protein (fig 1C, patient 5). 


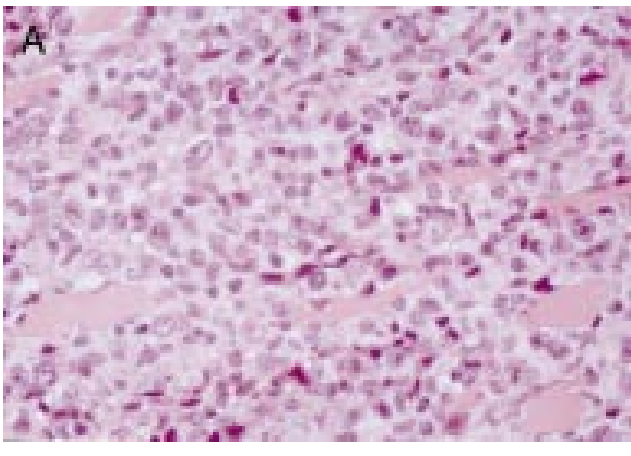

B

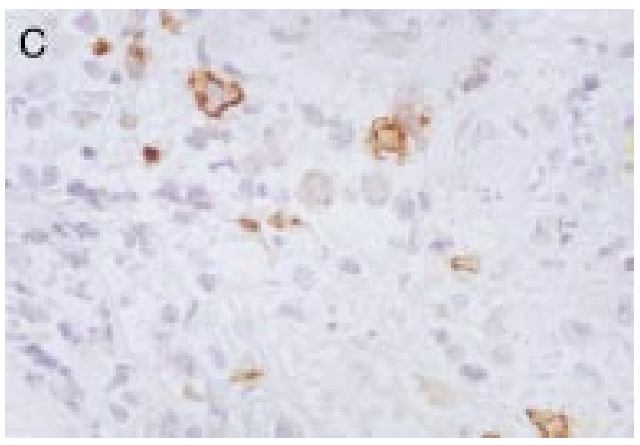

Figure 1(A) High grade diffuse large B cell lymphoma of the tonsil (patient 5). (B) Diffuse B cell lymphoma of the nasopharynx (patient 6). (C) Positive immunostaining for Epstein-Barr virus latent membrane protein (patient 5).

INCIDENCE OF NHL

The incidence of NHL in children with vertically acquired HIV infection less than 5 years of age born in England, Wales, and Scotland was estimated to be $14.2 / 1000$ each year. The observed number of cases (seven) in HIV infected children far exceeded the number expected in the general population (0.003), giving a rate ratio of 2288 ( $95 \%$ confidence interval 920 to 4715 ).

\section{Discussion}

The increased risk of malignant disease, particularly NHL and Kaposi's sarcoma, was recognised early in the HIV epidemic. By December $1994,6 \%$ of adult and $1.7 \%$ of paediatric AIDS indicator diseases in the USA were malignancies, approximately half of which were NHL. ${ }^{18}$ These figures almost certainly underestimate the overall incidence of malignant disease in infected subjects as up to one third of tumours may occur after the presentation of the first AIDS defining illness. ${ }^{19}$ Studies of children with HIV infection in Italy ${ }^{20}$ and the USA $^{21}$ have shown an overall prevalence of malignancy of 1.8 and $5 \%$, respectively, compared with a $3.6 \%$ prevalence of malignancy in our study. All 388 children in the Italian study acquired HIV infection from mother to child transmission. The US study of over 450 patients included children who had acquired HIV from transfusions of infected blood or blood products as well as those infected by mother to child transmission. The children were also possibly older and had more advanced disease than those in the Italian or UK studies, and the study was hospital rather than population based. All these factors may contribute to the higher overall prevalence of malignancy observed in the US study. NHL is the most common tumour type reported in all three studies.

Among children reported to AIDS surveillance programmes in the US and Europe up to 1993, Serraino and Franceschi reported that NHL occurred as a first AIDS indicator disease at almost twice the rate in black compared with white children, and twice as frequently in boys as in girls. ${ }^{8}$ No association between sex or ethnicity and NHL could be observed in either our study or the Italian study, but the overall number of children with NHL in the two studies was small.

In our study NHL developed before the age of 3 years in six of the seven children, a similar finding to the Italian study in which three of the five children with NHL were less than 2 years and all were less than 4 years of age at the diagnosis of NHL. This feature probably reflects the relatively young age of the HIV infected paediatric population in the two studies. Serraino and Franceschi reported a consistent increase in the frequency of NHL, as a first AIDS indicator disease, with age in both European and US surveillance data. $^{8}$ The interpretation of these results is, however, complicated by the inclusion of children acquiring HIV infection via routes other than mother to child transmission.

Four of the seven children in this study already had an AIDS indicator disease, and two of the remaining three were very immunosuppressed at the time NHL was diagnosed. All six children subsequently died of NHL within 14 months. The young age and rapid course of NHL in the children in this study may reflect rapidly progressive HIV disease, as observed in $20-25 \%$ of HIV infected children born to infected mothers. ${ }^{12}$ The only surviving child presented at an older age, had the classical histology of a Burkitt's lymphoma (high grade B cell lymphoma), and had a relatively higher CD4 count, a feature also reported in studies of HIV infected adults. ${ }^{5}$ The fact that this child survived intensive chemotherapy with no unusual infective complications and without the diagnosis of HIV infection being made is also evidence of a more intact immune system.

The immunological subtype of the tumours observed in this study is comparable with that reported in other HIV infected children and adults, and also in reports of NHL in children with other forms of congenital and acquired immune deficiencies. In all these situations the lymphomas are usually of B cell origin. The aetiology of NHL in the context of immunodeficiency is multifactorial, ${ }^{22}$ involving reduced 


\section{Key messages}

- There is an increased incidence of malignant disease, particularly NHL, in children with vertically acquired HIV infection

- In children affected with HIV less than 5 years of age, the incidence of NHL was about 2500 times greater than expected in the UK child population

- NHL tends to occur in advanced HIV disease and treatment is complicated by a high risk of infectious complications and poor underlying immune function. Management requires close cooperation between paediatric oncologists and infectious disease specialists

- Paediatricians now need to consider HIV infection as a predisposing cause of childhood cancer, especially NHL

immune surveillance allowing the escape of malignant cell clones and the activation of other viruses, particularly the Epstein-Barr virus, which is strongly associated with $\mathrm{B}$ cell lymphomas occurring in immunodeficient states and with nearly all cases of endemic Burkitt's lymphoma.

In this study, all three cases of NHL in which viral studies were undertaken were positive for Epstein-Barr virus latent membrane protein. In 1995 the UK Children's Cancer Study Group (CCSG) set up a study (lymphoproliferative disease protocol 9404) with the aims of studying the clinical, histological, and virological characteristics of NHL secondary to immune deficiency. The results from this study will provide a greater understanding of the mechanisms of NHL pathogenesis in children with immunodeficiency and will lead to the development of more successful approaches to the management of these very difficult cases. A systematic review of the histology of the patients in this study by the CCSG pathology review panel is planned and may provide clues about whether there are differences in the aetiology of NHL in HIV infected children compared with NHL secondary to other types of primary and secondary immune deficiency.

An overriding factor in the success in treating NHL in HIV infected subjects is the stage of the HIV disease itself. NHL is often a late stage development in HIV infection and the intensive combination chemotherapy currently recommended for many children with 'sporadic' NHL is inappropriate because of the underlying poor immune status of the patient and the high risk of infectious complications. Indeed, patient 1 developed major toxicity with one course of COMP chemotherapy and had only a limited response.

There is a need for collaboration between the national registers of cancers in children infected with HIV, which could provide an opportunity for research and the development of criteria for innovative approaches to treatment. Careful consultation is also required between the different subspecialties involved in the care of these children, including the multidisciplinary HIV team, infectious disease, and oncology subspecialists, so that decisions about treatment take account of the quality of life and are taken in the context of antiretroviral treatment and the treatment required for other HIV associated disorders. As cancer becomes more frequent in both adults and children living longer with HIV disease, there is a need for more trials of treatment for NHL. The small numbers of children are such that we will need to be guided by trials in adults, but we should not forget issues particular to children. We need to know when to treat and when to palliate, and, with treatment, how to minimise complications while achieving remission.

We thank Dr Charles Stiller for providing data on the incidence rates of NHL in childhood; Dr Ian Hann for providing information about the UK CCSG; Professor Catherine Peckham for comments on drafts of the paper; and Dr V Novelli, Dr M Sharland, Dr B Mandal, Dr I Lewis, and Dr P Holland for providing patient information. Dr M Malone provided the histopathology photographs. Ms T Berry undertook data management for the paediatric surveillance of HIV and AIDS in the UK, supported by the AIDS Education and Resarch Trust (AVERT) and Research Trust (AVERT) and the Department of Health. We thank all those paediatricians who contributed data to the BPASU reporting system. Dr D Gibb is supported by

1 Ioachim HL. The opportunistic tumors of immune

2 Keficiency. Adv Cancer Res 1990;54:301-17. Shapiro RS, Filipovich AH. Relationship of immunodeficiency to lymphoid malignancy. Pediatr Infect Dis f 1988;7(5):S10-S12.

3 Filipovich AH, Mathur A, Kamat D, Kersey JH, Shapiro RS. Lymphoproliferative disorders and other tumors complicating immunodeficiencies. Immunodeficiency 1994;5:91112 .

4 Abrams DI. Acquired immunodeficiency syndrome and related malignancies: a topical overview. Semin Oncol 1991; 18(5, suppl 7):41-5.

5 Biggar RJ, Rabkin CS. The epidemiology of acquired immunodeficiency syndrome-related lymphomas. Current Opinion in Oncology 1992;4:883-93.

6 Mandelblatt JS, Fahs M, Garibaldi K, Senie RT, Peterson HB. Association between HIV infection and cervical neoplasia: implications for clinical care of women at risk for neoplasia: implications for clinical care

7 both conditions. AIDS 1992;6:173-8. Epstein-Barr virus with leiomyosarcomas in young people with AIDS. N Engl f Med 1995;332:12-8.

8 Serraino D, Franceschi S. Kaposi's sarcoma and nonHodgkin's lymphomas in children and adolescents with AIDS. AIDS 1996;10:643-7.

9 Ades AE, Davison CF, Holland FJ, et al. Vertically transmitted HIV infection in the British Isles. BMF 1993;306:1296-9.

10 Stiller CA, Allen MB, Eatock EM. Childhood cancer in Britain: the National Registry of Childhood Tumours and incidence rates 1978-1987. Eur f Cancer 1995;31A:202834.

11 Brookmeyer R, Gail MH. AIDS epidemiology: a quantitative approach. Oxford: Oxford University Press, 1994:82-112.

12 The European Collaborative Study. Natural history of vertically acquired HIV-1 infection. Pediatrics 1994;94:815-9.

13 Communicable Disease Report. AIDS and HIV-1 infection in the United Kingdom: monthly report. CDR 1995;5:13942 .

14 Shinhgadia D, Howard MR, Brink NS, et al. Kaposi's sarcoma and KSHV [letter]. Lancet 1995;346:1359-60.

15 McCarthy GA, Kampmann B, Novelli V, Miller RF, Mercey $\mathrm{DE}, \mathrm{Gibb} \mathrm{D}$. Vertical transmission of Kaposi's sarcoma. Arch Dis Child 1996;74:455-7.

16 Lyall EGH, Langdale-Brown B, Eden OB, Mok JYQ, Croft NM. Ewing's sarcoma in a child with human immunodeficiency virus (type 1) infection. Med Pediatr Oncol 1993;21: 127-31.

17 European Collaborative Study. Age related standards for T-lymphocyte subsets based on uninfected children born to HIV-1 infected women. Pediatr Infect Dis f 1992;11:101826.

18 Centers for Disease Control and Prevention. US HIV and AIDS cases reported through December 1994. HIVIAIDS AIDS cases reported through December 1994.
Surveillance Report, Year-end Edition 1995;6:1.

19 Roithmann S, Tourani J-M, Andrieu J-M. AIDS associated non-Hodgkin's lymphoma. Lancet 1991;338:884-5.

20 Arico M, Caselli D, D'Argenio P, et al. Malignancies in children with human immunodeficiency virus type 1 infection. Cancer 1991;68:2473-7.

21 Mueller BU and Pizzo PA. Malignancies in pediatric AIDS. Curr Opin Pediatr 1996;8:45-9.

2 Herndier BG, Kaplan LD, McGrath MS. Pathogenesis of AIDS lymphomas. AIDS 1994;8:1025-49. 